\title{
Fostering Higher Academic Performance in African American Youth Through Enhanced Self-Efficacy: The Importance of Integrated Racial-Ethnic Identity
}

\author{
Eric Kyere \\ Indiana University School of Social Work \\ Sadaaki Fukui \\ Indiana University School of Social Work \\ James Holly Jr. \\ University of Michigan
}

\begin{abstract}
Although the dimensions that constitute racial-ethnic identity (REI) interrelate to affect psychosocial and academic outcomes, few studies have explored the nature (e.g., directionality) of these interrelations in understanding a strong and healthy REI among African American youth in relation to psychosocial and academic outcomes. In the current study, we applied path analysis to investigate the potential mediation effects of private regard in translating the effects of racial centrality and public regard to affect African American youth's academic performance through self-efficacy. Using a nationally representative sample of African American youth, findings suggest that racial centrality and public regard correlate to affect private regard, controlling for neighborhood safety and sociodemographic backgrounds. Private regard in turn, associated with self-efficacy to affect academic performance measured by GPA. These results indicate the need to investigate the potential mediation effects among REI dimensions to understand the nuanced pathways REI dimensions configure to form a strong and healthy REI to affect psychosocial and academic outcomes among African American youth.
\end{abstract}

Keywords: education, racial disparities, African American youth, racial-ethnic identity, self-efficacy, academic performance

\section{INTRODUCTION}

The K-12 education in the U.S is racially stratified because it is embedded within the racial landscape of the U.S society (Frankenberg et al., 2019; Lewis \& Diamond, 2015; Nasir, 2011). Within this racialized terrain of the K-12 education system, race shapes the way school practices legitimize, validate, and reward social and cultural capital that students bring to school (e.g., cultural capital, social networks; Diamond \& Lewis, 2019; Yosso, 2005). Thus, racial hierarchy is central to understanding the structure and cultural boundaries that determine possibilities (e.g., access to rigorous curriculum), including the kind of 
interactions and experiences that occur between and among students, staff, and teachers (Carter, 2018; Lewis \& Diamond, 2015).

The centrality of race in the K-12 educational landscape makes racial-ethnic identity critically important for understanding the educational experiences and outcomes of racial minorities (Rivas-Drake \& Umaña-Taylor, 2019). Racial-ethnic identity (REI) can be defined as the importance and subjective meaning individuals ascribe to their membership in the given racial-ethnic group in one's conceptualization of self (Cross, 1991; Schwartz et al., 2014; Sellers et al., 1998). For many minority youth, the racial subordinating contexts (including the school) within which they function have shown to inhibit beliefs related to their ability, aspiration, efficacy, and self-esteem as well as engagement and academic achievements (Huguley et al., 2019; Marks \& Garcia Coll, 2018; Spencer, 1999). Among such racial minorities are African American youth who have endured racially subordinating forces because of racism and negative stereotypes (Diamond, 2006; Dumas, 2014) whereby they continue to face discrimination (Erickson, 2016; Ford \& Moore, 2013; Gaddis \& Lauen, 2014; Milner, 2012) and stereotype threats (Leach \& Williams, 2007; Lindström et al., 2014; Steele \&Aaron, 1995; Steele, 1997). These experiences affect school engagement, perceived competence, and educational performance among African American youth (Kyere et al., 2020; Ogbu, 2004; Patterson, 2015; Steele, 1997; Superville, 2019) to persist decades of racial inequality in education.

To effectively counteract racism and respond well to the stereotype threats that many African American youth are likely to encounter in school and society in general, a strong and healthy racial-ethnic identity is critical (Huguley et al., 2019; Wright, 2011; Yip, 2018). For African American students, strong and healthy REI entails expunging negative stereotypical narratives that the racist society has constructed about African Americans (e.g., criminals, academically inferior, and culturally dysfunctional: Diamond \& Lewis, 2019; Erickson, 2016) and replacing such stereotypes with the positive views about Blacks/African Americans through their behavioral responses (e.g., academic engagement and achievement) (Singh, 2019; Worrell et al., 2006). REI directly affects the academic achievement of African American youth, and indirectly through its role in the psychosocial factors such as self-efficacy, motivation, and values, that influence academic achievement (Altschul, Oyserman \& Bybee, 2006; Butler-Barnes et al., 2013; Eccles, Wong \& Peck, 2006).

\section{THEORETICAL FRAMEWORK}

This study is informed by the multidimensional model of racial identity (Sellers, Smith, Shelton, Rowley, \& Chavous, 1998). According to the model, REI is central to understanding the psychosocial adjustment and development of functional competencies in African American youth in several domains of life including education (Rivas-Drake et al., 2014). Further, Sellers and colleagues $(1998,1997)$ have noted that within African Americans, REI consists of three dimensions that may be situationally stable. These three dimensions include: (1) Racial centrality - the importance attached to the racial group, (2) Racial regard-positive or negative feelings with which one views the Black racial group, and (3) Racial ideology - an individual's meaning making systems and attitudes relative to the racial group. Furthermore, racial regard consists of: (1) private regard, which describes one's positive or negative evaluation of self as part of the racial group, and (2) public regard, which indicates one's evaluation of others' view of the racial group and for that matter, themselves.

\section{Interrelations Among the Racial Identity Dimensions}

Sellers and colleague (1998)'s delineation of the various REI dimensions suggests that for the purpose of conceptual description, the various REI dimensions can be seen as distinct. However, in practice, they are interrelated (Galliher et al., 2017; Hughes et al., 2017; Sellers, et al., 1998). These interrelationships suggest that to comprehensively understand REI and how it affects youth development, the dimensions should be studied interactively. However, research has largely focused on the independent effects of each of the REI dimensions in assessing the effect of REI on the psychosocial and academic outcomes of African American youth (see Jones \& Neblett, 2016; Rowley et al., 1998; Yap et al., 2011 for review). We argue 
that in studies where the independent effects of each of the dimensions are explored simultaneously to identify which of them demonstrate strong and positive association with developmental outcomes, such as academic achievement, mental health, and behavior, there is a potential mediator among them. Yet, research has paid limited attention to the potential mediating effects that exist among the various REI dimensions in understanding the multidimensionality of REI construct.

A strong and healthy REI-REI that confers favorable psychological and academic outcomes on African American youth - which can entail interrelations among racial centrality, public regard, and private regard (Wright, 2011) is critical to activating self-efficacy, a key mechanism for understanding academic performance. Of particular interest is the role of public regard's relationship with racial centrality and private regard. Byrd and Chavous $(2012,2011)$ show that while positive racial climate (high public regard) strengthens private regard to affect higher self-efficacy beliefs and academic performance for African American youth, lower public regard may weaken private regard to affect academic outcome. Other researchers (Carter, 2008a, 2008b, 2012; Wright, 2011) have also shown that negative racial climate, which indicates low public regard, in association with high racial centrality and high private regard also seem to increase self-efficacy beliefs and performance. These studies suggest that African American youth with a strong and healthy REI, even negative racial climate maybe particularly important in activating agency to demonstrate their internalized sense of self as a way to provide a counter narrative to the deficit characterization of these youth because of their race (Martin, 2006; Marsh et al., 2012).

We draw on theoretical and empirical work that suggest that REI is a multidimensional construct, establishing interrelations among the dimensions (Chavous et al., 2003; Galliher et al., 2017; Hughes et al., 2017; Haper \& Tuckman, 2006; Sellers, et al., 1998) and research on positive racial-ethnic identity that have associated private regard to African American youth academic related outcomes (Butler-Barnes et al., 2017; Rowley et al., 1998; Yap et al., 2011). We contend that in instances where private regard has been strongly associated with positive psychosocial and academic outcomes (Huguley et al., 2019; Yap et al., 2011), when comparing the independent effects of the one of the REI dimensions, the other dimensions may be contributing to the strength of private regard. In this regard, the other REI dimension contribute to making private regard particularly influential to understand positive racial-ethnic identity, which has been shown to consistently confer favorable developmental outcomes on African American youth, and other youth of color (Huguley et al., 2019; Yap et al., 2011). This understanding shifts the focus away from analytic approaches that measure the independent effects of the REI dimensions while controlling for the effect of the others to one of integrated REI where we consider the contribution, the strength, and direction of each of the dimensions to understand strong and healthy or an integrated REI. Exploration of potential mediation relationship can be beneficial to both research and practice by highlighting the nature of contribution, strength, and direction of the REI dimensions to deepen our understanding of strong and positive REI among African American youth. It can also help clarify some of the mixed findings observed in the literature (Byrd \& Chavous, 2011; Chavous et al., 2003; Rowley et al., 1998; Yip, 2018) when multiple dimensions of REI and their independent effects are explored simultaneously.

The current study investigates the interrelations among three prominent REI dimensions (racial centrality, public regard, and private regard). Most importantly, the study examines whether private regards mediate the effects of racial centrality and public regard to affect academic performance (GPA) through self-efficacy among a sample of African American youth (See Figure 1 for conceptual model). The primary contribution of the current study to the literature is its examination of private regards' mediation of racial centrality and public regard in understanding the relationships between REI, self-efficacy, and academic performance of African American youth. Because the extant literature has largely investigated the independent effects of these REI dimensions, often with a focus on which among them is prominently associated with positive effects, research is limited in our understanding of the nuanced nature of the multidimensionality of the REI. Subsequently, we do not have a comprehensive understanding of the extent to which each dimension matter in the construction of a strong and healthy REI that confers favorable benefits on youth developmental outcomes. Using path analysis, the current study seeks to shed insight on the nature of the contributions and the directionality of three dimensions of REI to understand an integrated REI to affect academic outcomes in African American youth. 


\section{FIGURE 1 \\ CONCEPTUAL MODEL OF HOW REI DIMENSIONS INTERRELATE TO AFFECT GPA VIA SELF-EFFICACY}

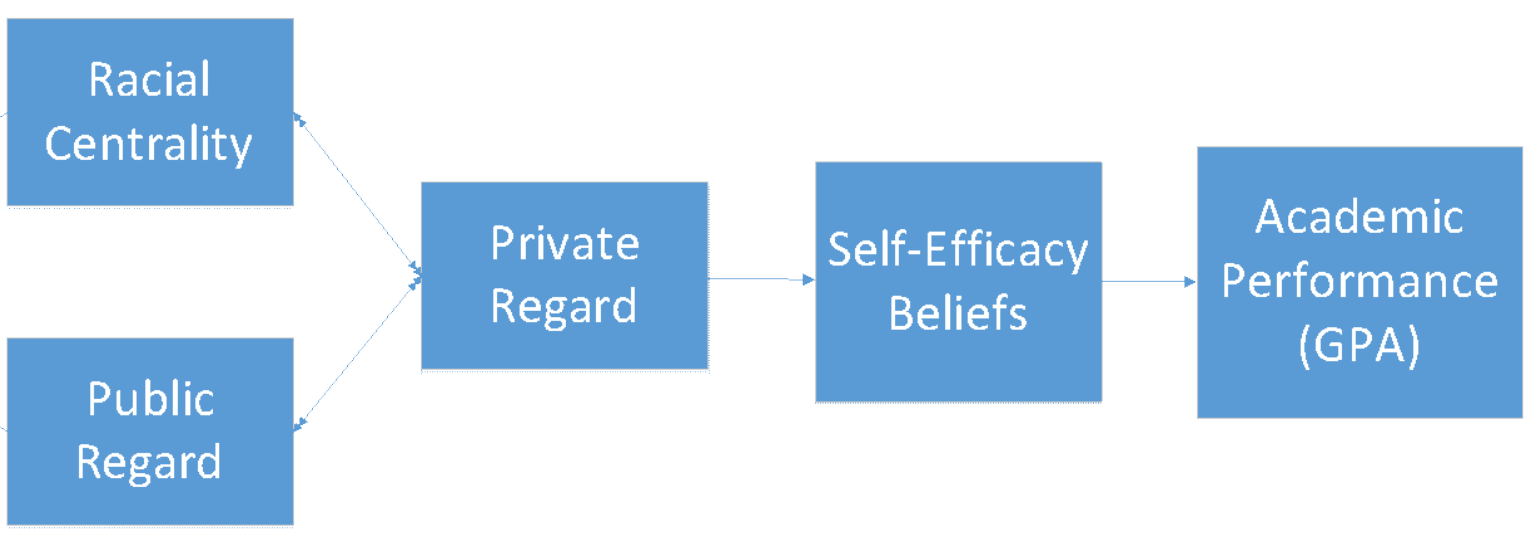

\section{LITERATURE REVIEW}

Few studies have shown that African American youth who demonstrate higher private regard and are in the school contexts that support their racial and self-beliefs (i.e., high public regard), had higher intrinsic motivations to achieve better academic outcomes. These students showed strong academic engagement compared with those with higher private regard but were in negative context (i.e., lower public regard: Byrd \& Chavous, 2012; 2011). Altschul, Oyserman and Bybee (2006) found that African American youth with strong connection to racial-ethnic group, which indicate racial centrality, had an achievement embedded orientation, suggesting an internalized sense of self that achievement is an in-group trait, and were aware of racism-lower public regard - achieved higher academic performance compared to those with low racial centrality and were unaware of racism. Qualitative studies have also showed that in a racially stigmatized context, an indication of lower public regard, REI dimensions likely interrelate to affect higher academic achievement (Carter, 2008a, 2008b, 2012; McGee \& Martin, 2011; McGee, 2015). For example, group connectedness, which indicates racial centrality, pride in self that suggests private regard, and an awareness of racism, which indicates public regard, characterize high achieving African American youth who also tend to be psychosocially healthy (Carter, 2008a, 2008b, 2012; Wright, 2011). Thus, the various REI dimensions interrelate to inform the construction of a strong and healthy REI of African American youth to affect their psychosocial and academic outcomes. However, further research is needed to unpack how REI dimensions configure to understand the development of strong and healthy REI with implications for psychological and academic outcomes among African American youth.

\section{REI, Self-Efficacy, and Academic Performance}

Self-efficacy, the belief in one's capabilities to perform a task in a given domain (Bandura, Barbaranelli, Caprara, \& Pastorelli, 1996; Eccles \& Wigfield, 2002), appears to be a central mechanism for understanding and articulating the influence of identity. Self-efficacy is critical to activating human agency within a causal structure that involves a reciprocal link between an individual, context, and behavior (Basili et al., 2020). It demonstrates individuals' perception about their capacity to overcome challenges, negotiate critical life transitions, discern among alternatives, and resist adversities to achieve desired goals (Basili et al., 2020). Self-efficacy is a critical factor to understanding academic outcomes through its direct link with performance and indirectly through several psychological processes that facilitate academic success (e.g. engagement motivations, expectancy beliefs, positive affect, and goal setting) (Bandura, Barbaranelli, Caprara, \& Pastorelli, 1996; Butler-Barnes, Chavous, Hurd \& Varner, 2013; Eccles \& Wigfield, 2002; Dogan, 2015; Schunk, 1991). 
Self-efficacy is a central but understudied element in African American students' outcomes (ButlerBarnes et al., 2013). Functioning within racially subordinating contexts (Diamond, 2006; Diamond \& Lewis, 2019) self-efficacy can be very beneficial to understanding sustained academic performance among African American youth. Therefore, identifying ways by which African American youth sustain efficacy beliefs to affect academic performance is important to inform practice that can strengthen youth's academic competencies (Butler-Barnes et al., 2017). Research has found association between African American youth's REI and their self-efficacy. For example, in the context of discrimination, racial centrality fosters higher academic self-efficacy among African American youth (Eccles, Wong \& Peck, 2006). Butler-Barnes et al. (2013) found that youth clustered in high self-acceptance, high private regard, and high self-efficacy demonstrated higher levels of academic persistence compared to those who were average and low on these constructs. In another study (Butler-Barnes et al., 2017), while private regard was negatively associated with oppositional academic identity - the notion that African American youth do not consider higher achievement to be an in-group trait and therefore minimize learning - the independent effect of racial centrality was positively associated with oppositional academic identity.

Overall, each of the dimensions that constitute REI as a multidimensional construct do matter in understanding the development of strong REI to affect psychosocial and academic outcomes of African American youth. This understanding calls for the need to investigate the interactive, rather than the independent effects of the REI dimensions in understanding the psychosocial and academic outcomes of African Americans. Because private regard has shown to be consistently associated with positive psychosocial and academic outcomes, examining potential mediation between private regard, racial centrality and public regard may shed insight into how racial centrality and public regard contribute to understanding strong and healthy REI among African American youth.

\section{CURRENT STUDY}

In the current study, drawing on the interrelations among REI dimensions, and the research (ButlerBarnes et al., 2017; Rowley et al., 1998; Yap et al., 2011) associating private regard to positive psychosocial and academic outcomes among African American youth, we investigate whether private regard mediate the effects of racial centrality and public regard to affect African American youth academic performance (GPA) through self-efficacy. We hypothesize that: (a) racial centrality is positively associated with private regard; (b) racial centrality is positively correlated with public regard; (c) public regard and private regard are significantly associated. This hypothesis is based on research suggesting that African American youth who have strong connection with their racial/ethnic group and internalized positive sense of themselves as academically capable use their achievement as a counter narrative in the context of racism (Altschul, Oyserman and Bybee, 2006; Carter, 2008a, 2012). (d) private regard will mediate the effects of racial centrality and public regard. Finally, private regard will have a positive direct association with self-efficacy, and indirect association with academic performance through the mediation effects of self-efficacy (see Figure 1 for conceptual model).

\section{METHODS}

The current study conducted secondary data analyses using the National Survey of American Life Adolescent Supplement (NSAL-A) 2001-2004 data, which were collected by the University of Michigan's Institute for Social Research (Cross, Taylor \& Chatters, 2018; Jackson, Caldwell, Antonucci \& Oyserman, 2016). The NSAL-A is a supplemental study of adolescents within the same adult households used in the National Survey of American Life (NSAL) study. The NSAL consists of a multistage probability sample of African Americans, Black Caribbean, and non-Hispanic Whites. Data were collected through face-to face interviews. In order to identify risk and protective factors that could prevent or perpetuate disorders classified by the Diagnostic and Statistical Manuel of Mental Disorders (DSM-IV). The NSAL-A dataset measured adolescents' health, social conditions, stressors, distress, racial identity, neighborhood conditions, school, and media activities. Several variables from the adult dataset (NSAL) were merged into the 
adolescent dataset (NSAL-A) within the same household. The current study used an African American sample $(n=810$, mean age $=15, S D=1.44)$.

\section{Measures}

Independent Variables

Racial identity (RI) was measured by the Multidimensional Inventory of Black Identity (MIBI, Sellers, Rowley, Chavous, Shelton, \& Smith, 1997), which consists of the racial centrality, public regard, and private regard subscales. Racial centrality, or the extent to which being Black was relevant to participants' self-concept consists of four items (e.g. being black is important to my self-image) (alpha =.71). Private regard, or youth's affective evaluation of being Black consists of four items (e.g., I am happy that I am black, I feel good about blacks) (alpha $=.82$ ). The public regard, or participants' evaluation of others/societal views of Blacks consists of four items (e.g., society respects blacks) (alpha =.72). For each subscale, participants responded on a four-point scale ranging from 1 (strongly disagree) to 4 (strongly agree). Previous study has established construct validity of this scale with African American youth (Sellers et al., 1997). Higher scores indicate higher levels of racial centrality, private regard, and public regard.

\section{Dependent Variables}

Student self-efficacy, and academic performance indicated by grade were the main dependent variables in the current study. Self-efficacy, which is used as mediating variable, was measured by a composite of 11 items developed from Pearlin and Schooler (1978)'s self-mastery scale (alpha $=.71$ ). Youth indicated the extent to which they believed certain statements were true about them. A sample question include: I have little control over what happens to me; there's little I can do to change things in life. Responses were coded from $1=$ strongly agreed to $4=$ strongly disagreed. Pearlin and Schooler (1978) have confirmed evidence of the psychometric property of the self-mastery scale with urban populations from older adolescents to adults including African Americans. Higher scores indicate higher self-efficacy. Students' GPA was assessed by students' report of their grades on a 5-point scale $1=\mathrm{A}$ to $5=\mathrm{F}$. It was reverse coded so that A represents the highest grade and $\mathrm{F}$ the lowest grade.

Covariates. We controlled for covariates that are likely to impact the REI dimensions as well as selfefficacy and academic performance. They include family income, neighborhood safety, gender, and age. Family income was captured by self-reports of family income taken from their adults' data in the same household. Participants were asked to indicate their income before taxes in the past 12 months from a range of options (from none through $\$ 1-\$ 999$ to $\$ 100,000$ or more). Scores were coded on a 6-anchored range scale starting from $0=$ none, $1=\$ 1-\$ 1,000 ; 2=\$ 1,001-\$ 25000$ to $6=$ over $\$ 100,000$. Neighborhood safety was assessed using a composite of seven items that asked youth how safe they felt about their neighborhood (alpha=.73). Sample questions include: 1) I feel safe in the neighborhood during the day; 2) Neighbors trust each other. Prior work suggests strong correlations among the items (Assari \& Caldwell, 2017). Responses were coded on a 4-point scale ranging from: 1$)=$ not at all true to $4=$ very true. Higher scores indicate that participants feel safe in their neighborhood. Gender was captured by the item that asked youth about their identified sex. Reponses were coded as $1=$ male $(48 \%)$ and $2=$ female $(52 \%)$. Age was assessed by youth's responses to the question, how old are you? Table 1 provides descriptive statistics of the study variables.

Analysis of Data. Descriptive statistics (see Table 1) and correlations were first examined for the RI dimensions, self-efficacy, and academic performance. Following, the research hypotheses were tested using a path analysis, including identification of significant direct pathways as well as effect decomposition analyses to estimate the indirect effects among parameters in the path model. Individual pathways were considered significant if regression coefficients were significant at .05 critical alpha-level. Overall model fit was assessed using model chi-square, root mean square error of approximation (RMSEA), the comparative fit index (CFI), and the Tucker-Lewis index (TLI). A critical value of $\geq .95$ was considered an acceptable fit threshold (Acock, 2013). Model fit indices were used to make any theoretically tenable model adjustments. Parameters were estimated using the full information maximum likelihood to account for missing data. All analyses were conducted using Stata 15 (Stata Corp, n.d). 


\section{RESULTS}

Correlation analysis revealed significant relationships among the study's variables in uncontrolled conditions (see Table 1). Inspection of the path analysis showed that the initial model indicated a poor fit, $\chi^{2}(15, N=789)=54.29, p<.001, C F I=.92, T L I=.80$, RMSEA $(90 \% \mathrm{CI})=.058(.042, .075)$. Information from the modification indices suggested that unaccounted for interrelations between the REI dimensions were the issues why the model accounted for too little variance in the expected underlying structure. Accordingly, theoretically plausible covariance paths were added from racial centrality to public regard (Sellers et al., 1998; Worrell et al., 2006). In addition, paths showing covariance between some of the covariates (e.g. neighborhood safety, family income, and age) and public regard were added in the model. The inclusion of these paths improved the fitness of the model to the acceptable levels $\left(\chi^{2}(11, N=789)\right.$ $=14.30, p=.217, C F I=.99, T L I=.98, R M S E A(90 \% \mathrm{CI})=0.02(0.00, .045)$, (see Figure 2$)$. The overall model accounted for $9 \%\left(R^{2}=.09\right)$ of the variability in African American youth's academic performance.

In terms of the interrelations among the REI dimensions examined, the findings suggested a positive relationship between racial centrality and public regard. Furthermore, private regard was positively associated with racial centrality $(\beta=.15, p<.001)$ and public regard $(\beta=.27, \mathrm{p}<.001)$ controlling for sociodemographic and neighborhood safety (see Figure 2 ). Private regard in turn, was positively associated with self-efficacy $(\beta=.14, p<.001)$, which also positively associated with academic performance $(\beta=.15$, $p<.001)$. The decomposition results suggested that private regard mediated the effects of both racial centrality and public regard to affect self-efficacy in a positive direction $(\beta=.07, \mathrm{p}<.001$, and $\beta=.04, p<.001$ respectively). Private regard indirectly affected academic performance through self-efficacy $(\beta=.02$, $p<.01)$. Furthermore, controlling for the mediation effect of private regard, the independent effects of racial centrality and public regard on self-efficacy were negative $(\beta=-.09, p<.01$ and $\beta=-.08, p<.01$ respectively). There was no direct link between any of the REI dimensions and student educational performance. These findings confirmed the study's hypotheses. 


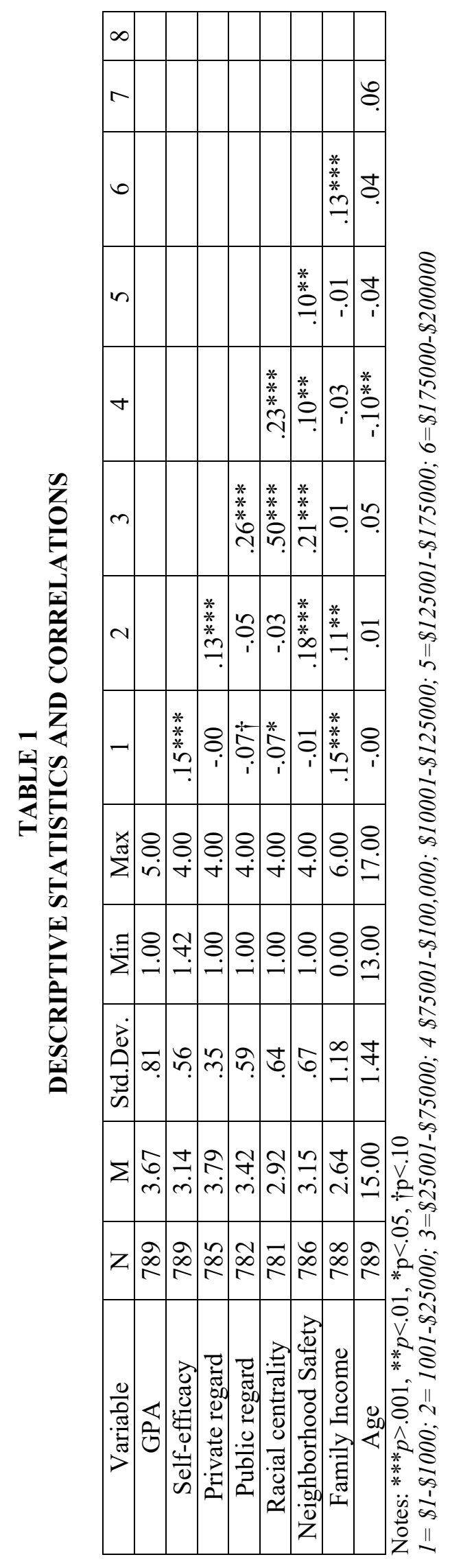

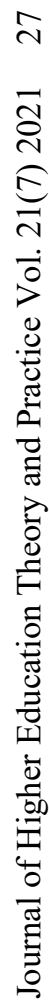




\section{FIGURE 2 \\ MECHANISM BY WHICH INTEGRATED RACIAL-ETHNIC IDENTITY INTERRELATE TO PREDICT PERFORMANCE THROUGH SELF-EFFICACY}

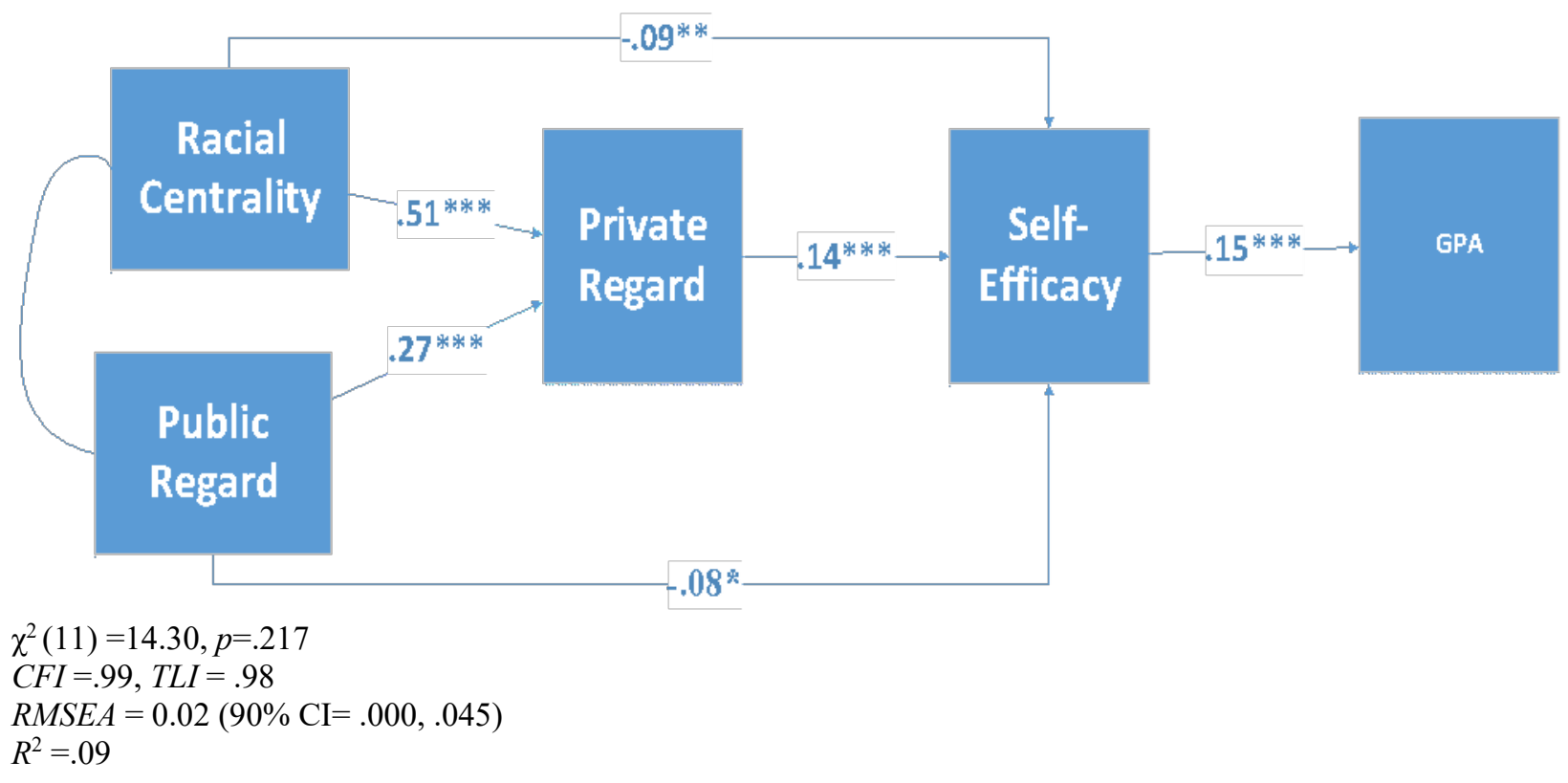

\section{DISCUSSION}

Guided by the multidimensional model of racial identity (Sellers et al., 1998), and research highlighting the prominence of private regard's positive association with African American youth psychosocial and academic outcomes, we designed this study to examine whether private regard mediates the effects of racial centrality and public regard to affect the academic performance of African American youth through the mediation effect of self-efficacy. The findings generally confirmed our hypotheses. First, racial centrality was positively associated with private regard, suggesting that African American youth examined, those who considered race to be important to their self-concept, indicated by the degree of their connection to the racial-ethnic group, were more likely to internalize a positive sense of themselves compared to those who regarded race to be of less importance. Second, racial centrality was positively related with public regard. Thus, as the youth's connection to the racial group grows stronger, they increasingly become aware of the public perception and treatment of the Black racial/ethnic group. Third, high public regard was positively associated with private regard, which suggests that a positive view of the public as appraised by the youth strengthens the internalized aspect of their racial/ethnic group in a positive way. Fourth, private regard was positively associated with self-efficacy, which in turn affected academic performance. That is, youth who internalized positive view of themselves, as members of the Black racial/ethnic group were more likely to display high self-efficacy compared to those who had low internalization, or did not internalize positive view of themselves, as members of the Black racial/ethnic group. The high self-efficacy in turn was positively associated with higher academic performance. Moreover, while racial centrality and public regard had direct negative association with self-efficacy, they both had significant indirect positive association with self-efficacy to affect academic performance through the mediation effect of private regard.

The findings confirm existing research that REI dimensions interrelate to contribute to a strong and healthy REI to affect African American youth's psychosocial and academic outcomes (Chavous et al., 2003; Murry et al., 2014; Rivas-Drake et al., 2014; Seaton, 2009). However, the nature of the contribution, strength, and direction of the various dimensions may differ. As observed (see Figure 2), private regard 
mediated the effects of racial centrality and public regard. However, the direct associations of racial centrality and public regard with self-efficacy were negatives. These present a nuanced understanding of how these REI dimensions behave to our understanding of the multidimensionality of REI. Thus, the various REI dimensions matter in unique ways in constructing a strong and healthy REI that confers favorable outcomes on African American youth's academic performance. These findings also indicate that rather than investigating the independent effects of the various REI dimensions to identify which one is prominent in understanding the process by which REI affects psychosocial and academic outcomes as noted in literature (Byrd \& Chavous, 2011; Chavous et al., 2003; Jones \& Neblett, 2016; Rowley et al., 1998), research that looks at the multiple pathways by which each of the dimensions contribute to a strong and healthy REI deepens our understanding of the nuanced ways REI dimensions configure and reconfigure to affect youth's development. In particular, research that examine potential mediation among the REI dimensions can help clarify some of the mixed findings (Cokley \& Chapman, 2008; Irving \& Hudley, 2008; Yip, 2018) especially when independent effects of the REI dimensions are examined simultaneously. Such research can inform practice about potential unique pathways to identify the benefits associated with each REI dimensions to support strong and healthy development of African American youth with implications for their psychosocial and academic outcomes. The positive association between racial centrality and private regard, and that of public regard and private regard suggest that REI affirming contexts (e.g. family, community, and school climate) are important psychosocial and educational resources for African American youth's academic achievement.

Research suggests that stereotypical racial narratives of African American youth intellectual inferiority operate in both the larger society and schools to undermine these youth educational engagement beliefs (Diamond \& Lewis, 2019; Kyere et al., 2020). The positive association between public regard and private regard suggests that practice and policy interventions that improve positive interracial contexts can strengthen African American youth's racial-ethnic identity to bolster their self-efficacy, which in turn can promote high academic achievement (Byrd \& Chavous, 2012).

\section{IMPLICATIONS FOR RESEARCH AND PRACTICE}

Our study has important implications for researchers, social workers, and educators. The findings imply that REI dimensions interrelate to influence self-efficacy and academic performance of African American youth. Research therefore needs to examine the interactive rather than the independent effects of the REI dimensions on youth's psychosocial and academic outcomes. Research on the interactive effects, in particular, mediations among the REI dimensions can shed more lights on the underlying mechanisms by which an integrated REI develops and can also explain some of the mixed findings in the extant literature. Next, the findings also highlight various ways by which social workers, parents, and educators can support an integrated racial-ethnic identity to positively affect African American youth's self-efficacy to enhance academic performance. More specifically, practice efforts that underscore the relevance of race, and support youth engagement with positive cultural heritage are likely to foster high private regard among African American youth. Additionally, given the positive correlation between racial centrality and public regard, and positive association between public regard and private regard, it is important that interventions to support African American youth thrive pay attention to stigma reduction through education that highlights the positive contributions of African Americans to society to promote high public regard toward African Americans. These processes in turn can bolster positive psychosocial and academic outcomes for African American youth.

As research on African Americans through the social identity theory and internalized racism framework has shown, African Americans tend to have strong connections with their racial groups. If this connection increases awareness of only their stigmatized status in society, they are likely to develop negative views about themselves. This negative view in turn may lower self-efficacy, and subsequently increase depressive symptomology (Hughes et al., 2015) and decrease academic performance (Steel, 1997). On the other hand, if the connection highlights awareness of and pride in their group's heritage and 
accomplishment, they are more likely to view themselves in a more positive light and seek ways to enact the positive self for engagement in social interactions.

Social workers can engage schools, educators, parents, and youth on racial literacy skills that raise awareness about the positive contribution of African Americans to society despite their racialized experiences (Stevenson \& Stevenson, 2014) and advocate for school climate and practices that honor their contributions. Research stemming from the possible self and identity-based motivation indicates that such an undertaking can strengthen African American youth's connection to histories of accomplishments by African Americans, to help them feel proud about being a member of their racial-ethnic group, and subsequently, develop similar achievement beliefs to bolster their psychosocial and academic adjustments (Oyserman \& Lewis, 2017; Oyserman, Bybee, \& Terry, 2006).

\section{LIMITATIONS}

This study is not without limitations. First, the data used in the current study are cross sectional. It is thus not certain if the current findings hold over time. Future study that uses longitudinal data (e.g., crosslagged and panel design) will help strengthen the current findings about the nature of interrelations among the REI dimensions. Next, although the current study underscores the need for an integrated REI through the interrelatedness of the various REI domains, we mainly examined two of these dimensions (racial centrality and subdimensions of racial regard: private and public regards). This was a limitation in the data set used, which did not have other REI dimensions. Research with a data set that allows for a more comprehensive examination of how the various REI dimensions interact is needed. In this regard, primary research that collects data on the various REI dimensions is also needed. Finally, conceptual understanding stipulates reciprocal relationships among the various racial-ethnic identity dimensions. However, in the current study, we partially explored this relationship between racial centrality and subdimensions of racial regard. In the light of these limitations, caution should be exercised in interpreting and generalizing the findings reported in the current study.

\section{CONCLUSION}

Despite the limitations, our study contributes to our understanding of African American youth's healthy integrated REI. More specifically, healthy REI is a function of the associations among the various REI dimensions, which have been studied independently in the majority of the prior studies. Moreover, the study shows that self-efficacy, which is a central mechanism for understanding students' academic performance, is an important outcome for assessing and articulating the impact of healthy integrated REI in African American youth. Consistent with prior work (Nasir et al., 2009), our study suggests that research and practices with African American youth that highlight the significance of race, engage in stigma reduction and support youth's engagement with their racial heritage, including African Americans' positive contributions to society can promote youth's positive view of themselves. The positive view of the self in turn can confer favorable psychosocial and academic outcomes among African American youth.

\section{REFERENCES}

Acock, A.C. (2013). Discovering structural equation modeling using Stata. Stata Press books. College Station, TX.

Assari, S., \& Caldwell, C.H. (2017). Neighborhood safety and major depressive disorder in a national sample of black youth; Gender by ethnic differences. Children, 4(2), 14.

Bandura, A., Barbaranelli, C., Caprara, G.V., \& Pastorelli, C. (1996). Multifaceted impact of self-efficacy beliefs on academic functioning. Child Development, 67(3), 1206-1222.

Butler-Barnes, S.T., Varner, F., Williams, A., \& Sellers, R. (2017). Academic identity: A longitudinal investigation of African American adolescents' academic persistence. Journal of Black Psychology, 43(7), 714-739. 
Butler-Barnes, S.T., Chavous, T.M., Hurd, N., \& Varner, F. (2013). African American adolescents' academic persistence: A strengths-based approach. Journal of Youth and Adolescence, 42(9), $1443-1458$.

Byrd, C., \& Chavous, T. (2012). The congruence between African American students' racial identity beliefs and their academic climates: Implications for academic motivation and achievement. In J.

Sulivan \& A. Esmail (Eds.), African American Racial Identity: An Interdisciplinary Exploration of the Racial and Cultural Dimensions of the Black Experience (pp. 345-369).

Byrd, C.M., \& Chavous, T. (2011). Racial identity, school racial climate, and school intrinsic motivation among African American youth: The importance of person-context congruence. Journal of Research on Adolescence, 21(4), 849-860.

Carter, D.J. (2008a). Achievement as resistance: The development of a critical race achievement ideology among black achievers. Harvard Educational Review, 78(3), 1-30.

Carter, D.J. (2008b). Cultivating a Critical Race Consciousness for African American School Success. Educational Foundations, 22, 11-28.

Carter, P.L. (2018). The multidimensional problems of educational inequality require multidimensional solutions. Educational Studies, 54(1), 1-16.

Chavous, T.M., Bernat, D.H., Schmeelk-Cone, K., Caldwell, C.H., Kohn-Wood, L., \& Zimmerman, M.A. (2003). Racial identity and academic attainment among African American adolescents. Child Development, 74(4), 1076-1090.

Cokley, K.O., \& Chapman, C. (2008). The roles of ethnic identity, anti-white attitudes, and academic selfconcept in African American student achievement. Social Psychology of Education, 11(4), 349365.

Diamond, J.B. (2006). Still separate and unequal: Examining race, opportunity, and school achievement in "integrated" suburbs. The Journal of Negro Education, 75(3), 495-505.

Diamond, J.B., \& Lewis, A.E. (2019). Race and discipline at a racially mixed high school: Status, capital, and the practice of organizational routines. Urban Education, 54(6), 831-859.

Dumas, M.J. (2014). 'Losing an arm': Schooling as a site of black suffering. Race Ethnicity and Education, 17(1), 1-29.

Eccles, J.S., Wong, C.A., \& Peck, S.C. (2006). Ethnicity as a social context for the development of African-American adolescents. Journal of School Psychology, 44(5), 407-426.

Eccles, J.S., \& Wigfield, A. (2002). Motivational Beliefs, Values, and Goals. Annual Review of Psychology, 53(1), 109-132.

Erickson, A.T. (2016). Making the Unequal Metropolis: School Desegregation and Its Limits. University of Chicago Press.

Frankenberg, E., Ee, J., Ayscue, J.B., \& Orfield, G. (2019). Harming our common future: America's segregated schools 65 years after Brown. Retrieved from www.civilrightsproject.ucla.edu

Ford, D.Y., \& Moore, J.L. (2013). Understanding and reversing underachievement, low achievement, and achievement gaps among high-ability African American males in urban school contexts. Urban Review, 45(4), 399-415.

Gaddis, S.M., \& Lauen, D.L. (2014). School accountability and the black-white test score gap. Social Science Research, 44, 15-31.

Galliher, R.V., McLean, K.C., \& Syed, M. (2017). An integrated developmental model for studying identity content in context. Developmental Psychology, 53(11), 2011.

Harper, B.E., \& Tuckman, B.W. (2006). Racial identity beliefs and academic achievement: Does being black hold students back? Social Psychology of Education, 9(4), 381-403.

Hughes, D.L., Del Toro, J., \& Way, N. (2017). Interrelations among dimensions of ethnic-racial identity during adolescence. Developmental Psychology, 53(11), 2139-2153.

Hughes, M., Kiecolt, K.J., Keith, V.M., \& Demo, D.H. (2015). Racial identity and well-being among African Americans. Social Psychology Quarterly, 78(1), 25-48. 
Huguley, J.P., Wang, M.T., Vasquez, A.C., \& Guo, J. (2019). Parental ethnic-racial socialization practices and the construction of children of color's ethnic-racial identity: A research synthesis and meta-analysis. Psychological Bulletin, 145(5), 437.

Irving, M.A., \& Hudley, C. (2008). Cultural identification and academic achievement among African American males. Journal of Advanced Academics, 19(4), 676-698.

Jackson, S.J., Caldwell, H.C., Antonucci, C.T., \& Oyserman, R.D. (2016). National survey of American life-Adolescent supplement (NSLAL-A), 2001-2004. Ann Arbor, MI: Inter-University Consortium for political and social research [distributor]. https://doi.org/10.3886/ICPSR36380.v1

Jones, S.C.T., \& Neblett, E.W. (2016). Racial-ethnic protective factors and mechanisms in psychosocial prevention and intervention programs for Black youth. Clinical Child and Family Psychology Review.

Kyere, E., Karikari, I., \& Teegen, B.C. (2020). The Associations Among Teacher Discrimination, Parents' and Peer Emotional Supports, and African American Youth's School Bonding. Families in Society, 101(4), 469-483.

Leach, M.T., \& Williams, S.A. (2007). The impact of the academic achievement gap on the African American family: A social inequality perspective. Journal of Human Behavior in the Social Environment, 15(2-3), 39-59.

Lewis, A.E., \& Diamond, J.B. (2015). Despite the best intentions: How racial inequality thrives in good schools. Oxford University Press.

Lindström, B., Selbing, I., Molapour, T., \& Olsson, A. (2014). Racial bias shapes social reinforcement learning. Psychological Science, 25(3), 711-9.

Marsh, K., Chaney, C., \& Jones, D. (2012). The strengths of high-achieving Black high school students in a racially diverse setting. The Journal of Negro Education, 81(1), 39-51.

Marks, A.K., \& Coll, C.G. (2018). Education and developmental competencies of ethnic minority children: Recent theoretical and methodological advances. Developmental Review, 50, 90-98.

Martin, D.B. (2006). Mathematics learning and participation as racialized forms of experience: African American parents speak on the struggle for mathematics literacy. Mathematical Thinking and Learning, 8(3), 197-229.

McGee, E.O. (2015). Robust and fragile mathematical identities: A framework for exploring racialized experiences and high achievement among black college students. Journal for Research in Mathematics Education, 46(5), 599-625.

McGee, E.O., \& Martin, D.B. (2011). "You would not believe what I have to go through to prove my intellectual value!" Stereotype management among academically successful Black mathematics and engineering students. American Educational Research Journal, 48(6), 1347-1389.

Milner, H.R. (2012). Beyond a test score: Explaining opportunity gaps in educational practice. Journal of Black Studies, 43(6), 693-718.

Murry, V.M., Berkel, C., Simons, R.L., Simons, L.G., \& Gibbons, F.X. (2014). A twelve-year longitudinal analysis of positive youth development among rural African American males. Journal of Research on Adolescence, 24(3), 512-525.

Nasir, N.I. (2011). Racialized identities: Race and achievement among African American youth. Stanford University Press.

Nasir, N.S., McLaughlin, M.W., \& Jones, A. (2009). What does it mean to be African American? Constructions of race and academic identity in an urban public high school. American Educational Research Journal, 46(1), 73-114.

Ogbu, J.U. (2004). Collective Identity and the Burden of "Acting White" in Black History, Community, and Education. The Urban Review, 36(1), 1-35.

Oyserman, D., \& Lewis, N.A. (2017). Seeing the destination and the path: Using identity-based motivation to understand and reduce racial disparities in academic achievement. Social Issues and Policy Review, 11(1), 159-194.

Oyserman, D., Bybee, D., \& Terry, K. (2006). Possible selves and academic outcomes: How and when possible selves impel action. Journal of Personality and Social Psychology, 91(1), 188-204. 
Patterson, O. (2015). The Cultural Matrix: Understanding Black Youth. Harvard University Press.

Pearlin, L.I., \& Schooler, C. (1978). The structure of coping. Journal of Health and Social Behavior, pp. $2-21$.

Rivas-Drake, D., \& Umaña-Taylor, J.A. (2019). Below the surface: Talking with teens about race, ethnicity, and identity. Princeton University Press.

Rivas-Drake, D., Seaton, E.K., Markstrom, C., Quintana, S., Syed, M., Lee, R.M., ... Sellers, R.M. (2014). Ethnic and racial identity in adolescence: Implications for psychosocial, academic, and health outcomes. Child Development, 85(1), 40-57.

Rowley, S.J., Sellers, R.M., Chavous, T.M., \& Smith, M.A. (1998). The relationship between racial identity and self-esteem in African American college and high school students. Journal of Personality and Social Psychology, 74(3), 715-724.

Seaton, E.K., \& Douglass, S. (2014). School diversity and racial discrimination among African-American adolescents. Cultural Diversity and Ethnic Minority Psychology, 20(2), 156-165.

Sellers, R.M., Smith, M.A., Shelton, J.N., Rowley, S.A., \& Chavous, T.M. (1998). Multidimensional model of racial identity: A reconceptualization of African American racial identity. Personality and Social Psychology Review: An Official Journal of the Society for Personality and Social Psychology, Inc., 2(1), 18-39.

Sellers, R.M., Rowley, S.A.J., Chavous, T.M., Shelton, J.N., \& Smith, M.A. (1997). Multidimensional Inventory of Black Identity: A preliminary investigation of reliability and construct validity. Journal of Personality and Social Psychology, 73(4), 805.

Singh, A.A. (2019). The racial healing handbook. New Harbinger Publications Inc.

Spencer, M.B. (1999). Social and cultural influences on school adjustment: The application of an identityfocused. Educational Psychologist, 34(1), 43-57.

StataCorp. (n.d.). Structural equation modeling: Stata reference manual: Release 15. College Station, TX. Retrieved from https://www.stata.com/search/

Steele, C.M. (1997). A threat in the air. How stereotypes shape intellectual identity and performance. The American Psychologist, 52(6), 613-629.

Steele, C.M., \& Aronson, J. (1995). Stereotype threat and the intellectual test performance of African Americans. Journal of Personality and Social Psychology, 69(5), 797-811.

Superville, R.D. (2019). Students give frank advice as to how to make school engaging. Education Week, $38(25), 3-5$.

Worrell, F.C. (2006). Generalizing nigrescence profiles: Cluster analyses of cross racial identity scale (CRIS) scores in three independent samples. The Counseling Psychologist, 34(4), 519-547.

Wright, B.L. (2011). I know who I am, do you?: Identity and academic achievement of successful African American male adolescents in an urban pilot high school in the United States. Urban Education, 46(4), 611-638.

Yap, S.C., Settles, I.H., \& Pratt-Hyatt, J.S. (2011). Mediators of the relationship between racial identity and life satisfaction in a community sample of African American women and men. Cultural Diversity and Ethnic Minority Psychology, 17(1), 89.

Yip, T. (2018). Ethnic/racial identity-A double-edged sword? Associations with discrimination and psychological outcomes. Current Directions in Psychological Science, 27(3), 170-175.

Yosso*, T.J. (2005). Whose culture has capital? A critical race theory discussion of community cultural wealth. Race Ethnicity and Education, 8(1), 69. 